\title{
FORMULASI INFUSAN DAUN SIRIH MERAH (Piper crocatum) SEBAGAI GEL ANTISEPTIK TANGAN
}

\author{
Wisnu Cahyo Prabowo*, Wahyu Widayat, Synthia Defriana \\ Laboratorium Biologi Farmasi, Fakultas Farmasi, Universitas Mulawarman, Samarinda \\ Corresponding author email: louwishnu@yahoo.com
}

\begin{abstract}
ABSTRAK
Melimpahnya sumberdaya alam Indonesia khususnya dalam pemanfaatannya sebagai bahan obat maupun kosmetik. formulasi sediaan obat tidak hanya mengandalkan bentuk fisik sediaan yang baik tetapi juga efektivitas/khasiat yang baik. Sasaran penelitian ini bertujuan untuk memperoleh sediaan gel antiseptik dengan bahan aktif daun sirih merah yang efektif membunuh mikroba ditangan serta daya hambat terhadap beberapa mikroba uji yang patogen. Bahan segar diekstraksi kemudian diformulasi dengan basis gel. Sediaan gel dengan berbagai konsentrasi diuji stabilitas berdasarkan penyimpanannya. Efektifitas sediaan tersebut di uji terhadap mikroba tangan dan beberapa mikroba patogen. Potensi efektifitas sediaan diperoleh dengan membandingkan dengan sediaan kontrol berbahan aktif etanol dan triklosan. Sediaan gel antiseptik ekstrak daun sirih merah baik stabil pada penyimpanan suhu $18-27^{\circ} \mathrm{C}$ dengan $\mathrm{pH} 5,5$ dan memiliki warna bening kekuningan. Konsentrasi sediaan gel antiseptik efektif pada 25\% terhadap mikroba tangan yang setara dengan handsanitizer alkohol, sedangkan pada konsentrasi efektif 15\% terhadap Candida albican; konsentrasi 20\% terhadap Candida utilis; dan 25\% terhadap Vibrio cholera, keseluruhannya setara dengan handsanitizer alkohol.
\end{abstract}

Kata Kunci : Gel Antiseptik, Sirih Merah, Piper Crocatum

DOI: https://doi.org/10.25026/jsk.v1i10.59

\section{PENDAHULUAN}

Gel antiseptik tangan di masyarakat sekarang ini telah menjadi gaya hidup modern. Perkembangan ini dikarenakan prinsip hidup bersih, terhindar dari penyakit dan pemakaian yang praktis. Beberapa sediaan paten gel antiseptik tangan telah banyak dijumpai di pasaran dengan bahan aktif seperti alkohol (etanol, propanol, isopropanol) dengan konsentrasi $\pm 50 \%$ sampai $70 \%$, dan jenis desinfektan lain seperti: klorheksin dan triklosan ${ }^{[2]}$. Daun sirih merah (Piper crocatum) sebagai antiseptik tradisional yang sering digunakan oleh masyarakat Indonesia dapat menggantikan bahan obat sintetik tersebut. Melihat kemanfaatannya, persyaratan keamanan, serta lebih terhindar dari efek samping yang ditimbulkan obat sintetik maka pengembangan pengobatan bahan alam mulai banyak disukai ${ }^{[3]}$. Dalam pembuatan sediaan obat herbal, keamanan dan efektifitas suatu obat bahan alam harus mempertimbangkan formulasi atau rancangan dari suatu bentuk sediaan yang tepat dengan pertimbangan karateristik fisika, kimia dan biologis dari setiap bahan-bahan obat dan bahan farmasetika yang akan digunakan dalam membuat produk ${ }^{[1]}$.

\section{METODE PENELITIAN}

\section{Sampel dan Bahan}

Sampel bawang daun sirih merah segar diperoleh di desa loa ipuh, kecamatan Tenggarong, Kutai Kartanegara, Kal-Tim, Bahan penelitian antara lain, Aquades, alkohol $70^{\circ} \mathrm{C}$, blue berry, ekstrak daun sirih merah, mikroba uji Bacillus subtilis, Candida albicans, Candida utilis, Echeresia coli, Pseudomonas aeroginosa, Salmonella thyposa, Staphyloccocus aureus Streptoccocus epidermidis dan Vibrio cholerae, nutrient agar, potato dekstrosa 
agar, sediaan gel antiseptik dengan bahan aktif etanol dan triklosan, Carbopol 940, Gliserin, Natrium metabisulfit, dan Trietinolamin.

\section{Peralatan}

Peralatan yang digunakan antara lain, autoclav, colony counter, inkubator, kertas saring, laminar air flow, mikrometer skrup, mortir, oven, paper disc, seperangkat alat gelas, timbangan analitik.

\section{Prosedur}

\section{a. Penyiapan Sampel Uji}

Daun tanaman sirih merah segar dicuci dan dibersihkan, dipotong kecilkecil, kemudian dimasukkan dalam wadah tertutup. Sampel segar sebanyak 50 gram diekstraksi dengan cara infusa di dalam panci yang berisi aquades sebanyak $100 \mathrm{~mL}$. Sampel dipanaskan dalam penangas air selama 15 menit suhu 90-98 ${ }^{\circ} \mathrm{C}$ sambil lalu diaduk, kemudian diperas selagi panas dengan kain flanel di dalam labu ukur, tambakan aquades yang telah dipanaskan secukupnya melalui residu hingga diperoleh volume $100 \mathrm{~mL}$.

\section{b. Penyiapan Mikroba Uji}

Biakan mikroba hasil inokulasi disuspensikan dengan menggunakan $\mathrm{NaCl}$ 0,9\%. Sesuai standar Mc Farland, suspensi diukur transmitannya pada $25 \% \mathrm{~T}$ untuk bakteri dan $75 \% \mathrm{~T}$ untuk khamir.

\section{c. Uji Antimikroba ekstrak}

Campuran medium (NA untuk bakteri dan PDA untuk jamur) dengan masing-masing variasi konsentrasi ekstrak mulai dari rendah hingga konsentrasi tinggi, kemudian dituang ke dalam cawan petri steril dan dibiarkan memadat. Setelah memadat digores di atas permukaan (metode surface place)dengan masing-masing mikroba uji pada zona yang berbeda lalu diinkubasikan, kemudian dilakukan pengamatan pada media. Ekstrak dikatakan aktif jika tidak ada pertumbuhan mikroba uji pada permukaan medium.

\section{d. Pembuatan Sediaan Gel}

Cara pembuatan formula sediaan gel antiseptik tersebut dilakukan sebagai berikut; Carbopol 940 dikembangkan dalam air panas, kemudian diaduk. Kedalam campuran tersebut, ditambahkan TEA sambil diaduk perlahan sampai terbentuk gel yang jernih serta ditambahkan gliserin. Sari daun sirih merah sesuai konsentrasi yang diinginkan dicampur dengan natrium metabisulfit kemudian dimasukkan ke dalam basis gel. Dicukupkan volumenya dengan aquades hingga $60 \mathrm{~mL}$. Diberikan essens blue berry.

\section{e. Uji Stabilitas}

Dilakukan penyimpanan sediaan gel yang telah dibuat pada suhu $18^{\circ} \mathrm{C}$, $27^{\circ} \mathrm{C}$, dan $37^{\circ} \mathrm{C}$ selama 30 hari. Pengujian tingkat kepekatan warna dilakukan dengan membandingkan setiap perbedaan warna pada masing-masing konsentrasi formula sediaan gel yang berbeda. Pengujian $\mathrm{pH}$ sediaan gel dilakukan dengan menggunakan kertas $\mathrm{pH}$ sebagai indikator asam-basa.Hasil analisis dibandingkan menggunakan marker senyawa dan pustaka untuk mengetahui karakteristik senyawa yang diperoleh.

\section{f. Pengujian Efektivitas Antiseptik Sediaan}

Telapak tangan dicuci dengan air kran, kemudian dikeringkan. Telapak tangan dioleskan dengan sediaan gel ekstrak daun sirih merah. Selanjutnya sidik ibu jari ditempelkan pada media padat dalam cawan petri. Media diinkubasi dan diamati koloni pertumbuhan mikroba. Untuk masingmasing sediaan gel kontrol (gel triklosan dan alkohol) juga diperlakukan sama dengan sediaan uji. 


\section{g. Uji Daya Hambat terhadap Mikroba Uji \\ Dibuat medium NA dan PDA,} setiap cawan petri dituangkan medium sebanyak $10 \mathrm{~mL}$ yang telah dicampur mikroba uji sebanyak $20 \mu \mathrm{L}$, biarkan hingga memadat, kemudian dibagi 6 zona untuk masing-masing sediaan uji. Masing-masing paper disc steril diletakkan kedalam formula sediaan gel. Diletakkan paper disc pada masingmasing zona di atas permukaan medium, diinkubasikan dan diukur zona bening masing-masing sediaan uji. Untuk masing-masing sediaan gel kontrol juga diperlakukan sama pada cawan petri yang sama. Potensi antimikroba diukur dengan membandingkan dengan control sediaan gel berbahan aktif alcohol dan triklosan. Signifikansi data dianalisis menggunakan anova dan dilanjutkan menggunakan uji t.

\section{HASIL DAN PEMBAHASAN}

\section{Skrining Mikrobiologis}

Hasil skrining mikrobiologis terhadap beberapa bakteri uji yang patogen menunjukkan aktifitas antiseptik ekstrak pada mikroba vibrio chollera, salmonella typossa, staphylococcus aureus, candida albican dan candida utilis.

Konsentrasi bahan aktif memiliki potensi untuk diformulasikan dalam sediaan gel antiseptik dengan sedikit peningkatan konsentrasi. Formulasi sediaan gel dibuat dengan komposisi pada tabel 2.

Secara organoleptis, sediaan gel yang diperoleh mempunyai warna kekuningan hingga kemerahan. Sediaan gel yang dibuat sesuai formula, mempunyai karakter organoleptis berwarna merah muda-merah, berbau blue berry (zat pengaroma) dan jernih. Berdasarkan hasil pengamatan $\mathrm{pH}$ selama 4 minggu tidak ada perubahan yang terjadi. Kemungkinan basis gel diformulasi telah cukup stabil dan tidak terjadi reaksi yang menyebabkan perubahan kimia komponen gel antiseptik. Pada penggunaan carbopol sebagai basis gel, keasaman sangat diperhatikan. Penggunaan triethanolamin (TEA) digunakan sebagai zat penetralisasi carbopol pada suasana sedikit asam tersebut.

Pengaruh penyimpanan yang berbeda, mempengaruhi perubahan warna. Pada penyimpanan disuhu $37^{\circ} \mathrm{C}$ terlihat lebih cepat teroksidasi dibanding pada suhu ruangan dan pada suhu dingin sediaan gel sangatlah stabil. Reaksi oksidasi mungkin terjadi karena faktor pemanasan yang ditandai berubahnya warna sediaan.

\section{Efektifitas Antiseptik Formula Gel}

Pengujian efektifitas gel merupakan suatu ukuran dalam menimbulkan efek langsung pada mikroba yang terdapat pada tangan.

Tabel 1.Hasil skrining mikrobiologis ekstrak daun sirih merah

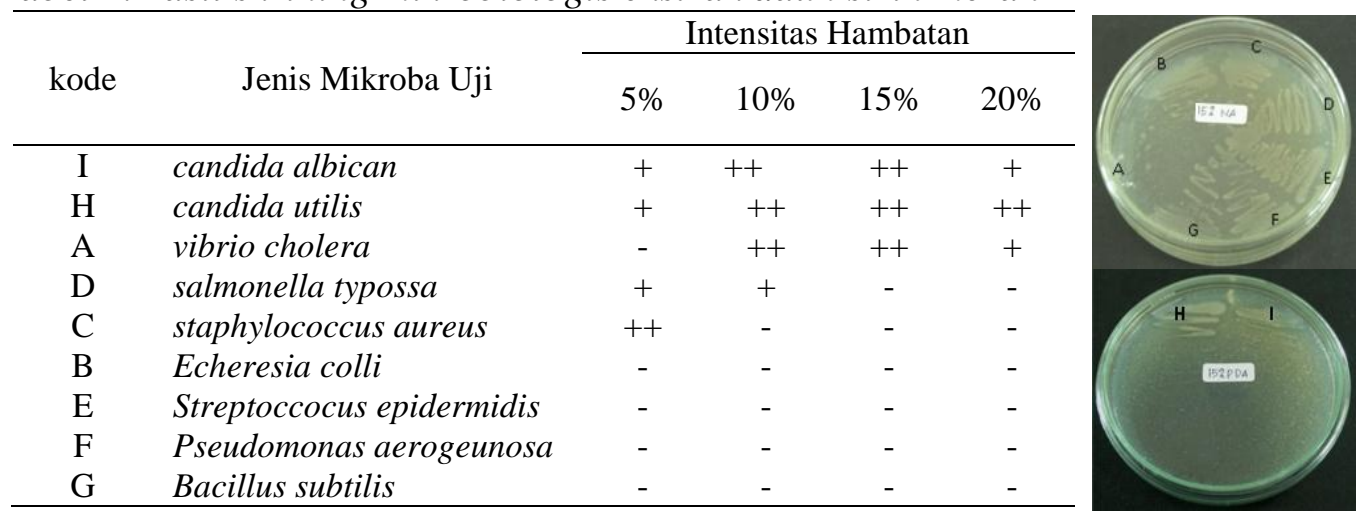




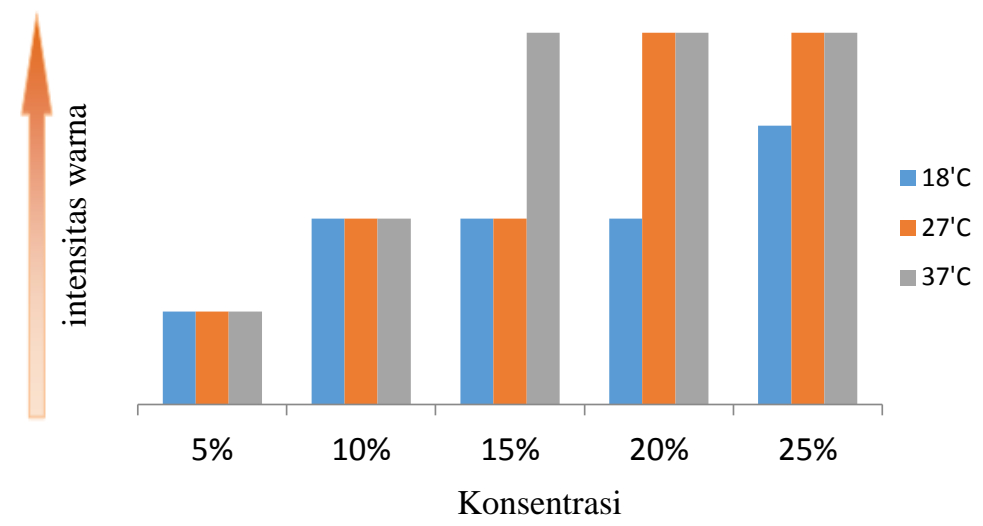

Gambar 1. Intensitas kepekatan warna sediaan gel disetiap penyimpanan

\section{Formulasi dan Stabilitas Sediaan}

Tabel 2. Formula sediaan gel antiseptik tangan ekstrak daun sirih merah (kiri) ${ }^{[4]}$, hasil sediaan jadi (kanan).

\begin{tabular}{lcc}
\hline \multicolumn{1}{c}{ Bahan } & Formula 1- 6 \\
\hline Ekstrak daun sirih merah & $5 \%, 10 \%, 15 \%, 20 \%$ dan $25 \%$ \\
Carbopol 940 & $0,8 \%$ \\
TEA (Trietinolamin) & $1,6 \%$ \\
Gliserin & $19 \%$ \\
Blue berry & $2 \mathrm{gtt}$ \\
Natrium metabisulfit & $0,5 \%$ \\
Aquades ad. & ad $60 \mathrm{~mL}$
\end{tabular}
$\mathrm{A}=$ kadar ekstrak 5\%,
D = kadar ekstrak $20 \%$
$\mathrm{B}=$ kadar ekstrak $10 \%$
$\mathrm{E}=$ kadar ekstrak $25 \%$
$\mathrm{C}=$ kadar ekstrak $15 \%, \quad \mathrm{~F}-\mathrm{G}=$ Replikasi

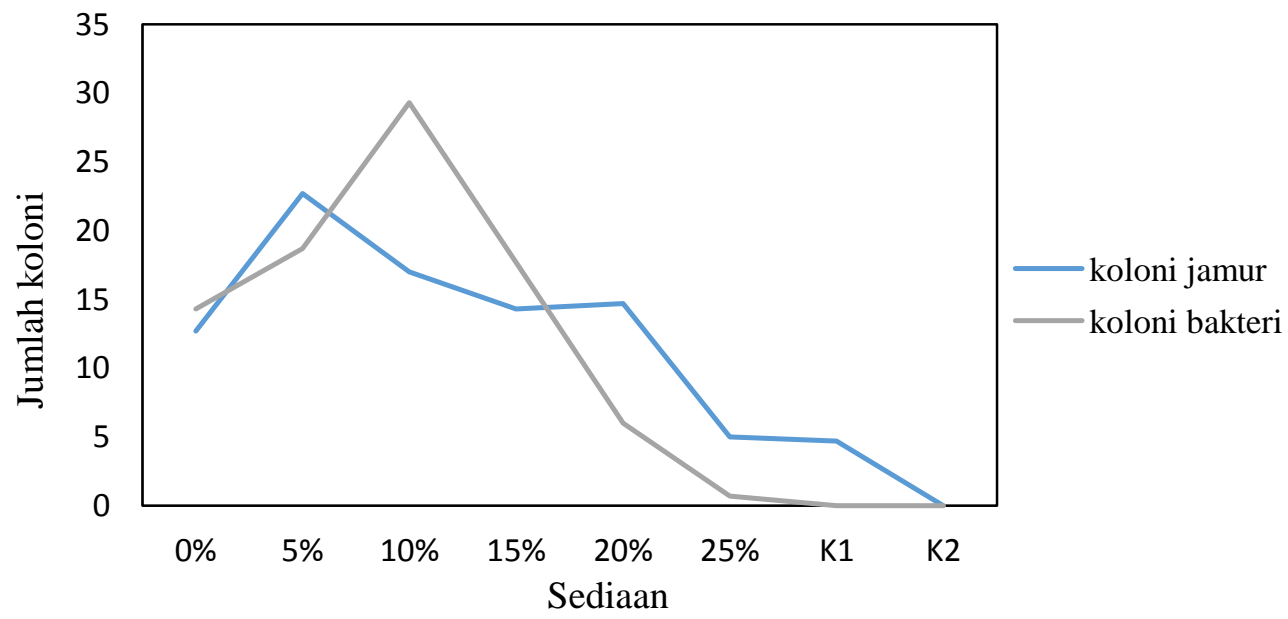

Gambar 2. Hasil uji antiseptik terhadap mikroba tangan

Hasil pengujian efektifitas antiseptik terhadap mikroba cukup memperllihatkan hasil pada beberapa konsentrasi zat aktif. Jika dibandingkan dengan sediaan gel berbahan aktif alkohol dan triklosan, terlihat kekuatan 
antiseptik sediaan terhadap jamur pada konsentrasi $25 \%$ terlihat sama baik. Hal ini menandakan kandungan senyawa aktif pada daun sirih merah sangat efektif menghambat aktifitas pertumbuhan jamur.

\section{Daya Hambat Sediaan Gel}

Berdasarkan hasil skrining diatas diketahui 5 jenis mikroba saja yang mampu di hambat pertumbuhannya oleh formulasi gel antiseptik ini, dan setelah dilanjutkan dengan pengujian daya hambat ternyata hanya 3 jenis mikroba yang mampu dihambat pertumbuhannya. Berdasarkan analisis statistik, diperoleh hasil daya hambat formula gel antiseptik dibandingkan dengan kontrol.
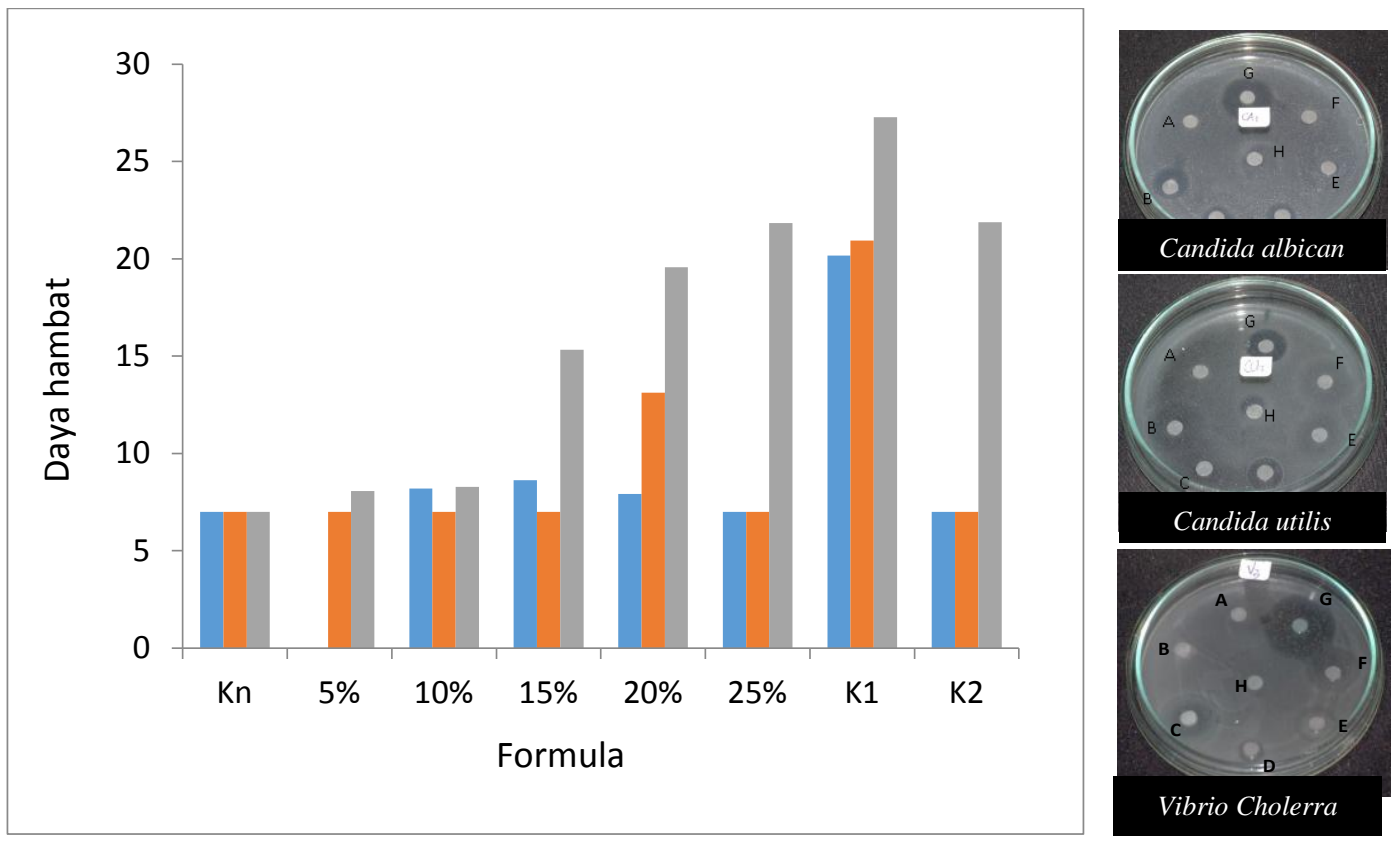
Ket:
A $: 5 \%$
B : $10 \%$
F : kontrol positif Alkohol handsanitizer / K2
C : $15 \%$
G : kontrol positif Triklosan handsanitizer / K1
D : $20 \%$
$\mathrm{H}$ : kontrol negatif (basis gel) / Kn
$\mathrm{E}: 25 \%$

Hasil pengujian daya hambat formula gel antiseptik dengan berbagai konsentrasi

Hasil efektifitas formula gel antiseptik daun sirih merah terhadap candida utilis lebih baik pada konsentrasi $20 \%$ dibandingkan konsentrasi yang lain serta kontrol 2, tetapi tidak lebih baik dibandingkan kontrol 1. Sedangkan terhadap vibrio cholera terlihat mempunyai efektifitas pada konsentrasi formula gel antiseptik daun sirih merah pada konsentrasi tertinggi yaitu $25 \%$. Nilainya sama kuat dibanding dengan kontrol 1 tetapi tetap tidak lebih baik dibanding kontrol 2.

\section{KESIMPULAN}

Sediaan gel antiseptik ekstrak daun sirih merah baik dengan stabilitas penyimpanan pada suhu $18-27^{\circ} \mathrm{C}$ dengan pH 5,5 dan warna bening kekuningan. Konsentrasi sediaan gel antiseptik efektif pada $25 \%$ terhadap mikroba tangan setara dengan handsanitizer alkohol. Efektifitas sediaan gel antiseptik konsentrasi 15\% 
terhadap Candida albican; konsentrasi $20 \%$ terhadap Candida utilis; dan 25\% terhadap Vibrio cholera, keseluruhan setara dengan handsanitizer alkohol.

\section{UCAPAN TERIMA KASIH}

Penelitian ini terwujud berkat dukungan Laboratorium Biologi Farmasi, serta kerja sama DIKTI pada kegiatan Pekan Kreatifitas Mahasiswa Penelitian (PKP-P).

\section{DAFTAR PUSTAKA}

[1]. Ansel C, 2005. Pengantar Bentuk Sediaan Farmasi. UI-Press; Jakarta. Hal. 143

[2]. Gennaro, A.R. 1995. Remington: The Science and Practice of Pharmacy, Vol. II. Mack Publishing Company, Pennsylvanis. P. 1263 -1270 .

[3]. Goeswin A, 2007. Teknologi Bahan Alam. ITB; Bandung, Hlm 8-9

[4]. Rowe C. 2004. The Handbook of Pharmaceutical Excipient, Pharmaceutical Press and the American Pharmacists Association; USA 